\title{
Structural and Magnetic Properties of Nanopowders and Coatings of Carbon-Doped Zinc Oxide Prepared by Pulsed Electron Beam Evaporation
}

\author{
V. G. Il'ves ${ }^{1,2}$ and S. Yu. Sokovnin ${ }^{1,2}$ \\ ${ }^{1}$ Institute of Electrophysics, Ural Branch of the Russian Academy of Sciences, Yekaterinburg, Russia \\ ${ }^{2}$ Ural Federal University Named after the First President of Russia B. N. Yeltsin, Yekaterinburg, Russia \\ Correspondence should be addressed to V. G. Il'ves; ilves@iep.uran.ru
}

Received 21 June 2016; Revised 11 November 2016; Accepted 8 December 2016; Published 23 April 2017

Academic Editor: Yoke K. Yap

Copyright (C) 2017 V. G. Il'ves and S. Yu. Sokovnin. This is an open access article distributed under the Creative Commons Attribution License, which permits unrestricted use, distribution, and reproduction in any medium, provided the original work is properly cited.

\begin{abstract}
With the help of electron beam evaporation of mechanical mixtures of nonmagnetic micron powders $\mathrm{ZnO}$ and carbon in vacuum with the subsequent annealing of evaporation products in air at the temperature of $773 \mathrm{~K}$, single-phase crystal nanopowders $\mathrm{ZnO}$ $\mathrm{C}$ were produced with the hexagonal wurtzite structure and low content of the carbon dopant not exceeding $0.25 \mathrm{wt} \%$. It was established that doping $\mathrm{ZnO}$ with carbon stimulates primary growth of nanoparticles along the direction $\langle 0001\rangle$ in the coatings. Nanocrystal growth in coatings occurs in the same way as crystal growth in thin films, with growth anisotropy in the $c$-axis direction in wurtzite $\mathrm{ZnO}$. Element mapping has confirmed homogeneous distribution of carbon in $\mathrm{ZnO}$ lattice. Ferromagnetism of singlephase crystal nanopowders $\mathrm{ZnO}-\mathrm{C}$ with the hexagonal wurtzite structure and low content of the carbon dopant not exceeding $0.25 \mathrm{wt} \%$ was produced at room temperature. Ferromagnetic response of the doped NP $\mathrm{ZnO}-\mathrm{C}$ has exceeded the ferromagnetic response of pure NP ZnO 5 times. The anhysteretic form of magnetization curves $\mathrm{NP} \mathrm{ZnO}-\mathrm{C}$ indicates aspiration of samples to superparamagnetism manifestation.
\end{abstract}

\section{Introduction}

The diluted magnetic semiconductors (DMS) cause huge interest due to their potential use in devices of spintronics $[1,2]$. In particular, magnetism of nondoped $\mathrm{ZnO}$ is the object of scientific debates because d-orbitals of $\mathrm{Zn}$ in nonmagnetic stoichiometric $\mathrm{ZnO}$ are completely filled [3]. Occurrence of ferromagnetism at the room temperature (RTFM) in $\mathrm{ZnO}$ is connected to the presence of oxygen vacancies $\left(V_{\mathrm{O}}\right)[4,5]$, vacancies of $\mathrm{Zn}\left(V_{\mathrm{Zn}}\right)[6,7]$, and interstitial atoms $\mathrm{Zn}\left(\mathrm{Zn}_{\mathrm{i}}\right)$ [8]. It is theoretically shown $[9,10]$ that $V_{\mathrm{Zn}}$ has the magnetic moment. Xing et al. [11] reported RTFM in $\mathrm{ZnO}$ nanowires and attributed it to the presence of oxygen vacancies. Detailed theoretical research of the vacancy-induced magnetism in $\mathrm{ZnO}$ thin films has shown $[12,13]$ that RTFM of films occurs due to $V_{\mathrm{Zn}}$, but not due to $V_{\mathrm{O}}$.

Various methods were used for synthesis of nanoparticles and films of $\mathrm{ZnO}-\mathrm{C}$. In calculations, Pan et al. [13] have predicted RTFM in C-doped wurtzite $\mathrm{ZnO}$ and then, by means of pulsed laser deposition (PLD), produced $\mathrm{ZnO}-\mathrm{C}$ films with the Curie temperature over $403 \mathrm{~K}$. Zhou et al. [14] received $\mathrm{ZnO}-\mathrm{C}$ films with RTFM by means of ionic implantation. From this point on, publications about detection of RTFM in carbon-doped $\mathrm{ZnO}$ began to appear even more frequently [15-20]. Enhancement of room temperature ferromagnetism in C-doped $\mathrm{ZnO}$ films by nitrogen codoping was described in [21].

The coexistence of two ferromagnetic phases $\mathrm{ZnO}$ in the carbon-doped nanoparticles of $\mathrm{ZnO}$ produced by the zol-gel method with two points of the Curie $(>773 \mathrm{~K})$ and metamagnetic transformation in the magnetic field of $H$ $=19.2 \mathrm{kOe}$ is shown in the study [22]. However, the main issue is the origin of the magnetic moment in the $\mathrm{ZnO}-\mathrm{C}$ system because it has no magnetic dopants of transitional elements. Therefore, it is impossible to neglect the role of internal defects in pure $\mathrm{ZnO}$, for which strong correlation between defects and magnetization is proved in numerous works [23]. Occurrence of RTFM in various nanomaterials is 
influenced by a large number of factors; in particular, the way of nanomaterials receipt strongly influences their magnetic properties [24].

Electron beam is a powerful tool for the creation of defects in a solid state. Nevertheless, there are few researches of RTFM in DMS, such as in ZnO-based nanomaterials, which were carried out with the use of an electron beam [25-29]. At the same time, electron beam of electronic microscopes [30] is frequently used for the modification of semiconductors or for receiving high-quality thin films [31,32] on electronic installations based on channel spark-type discharge.

Relativistic electron beam is successfully used for receiving nanoparticles of various compounds in industrial-andtrial volume in the installation on the basis of the industrial accelerator with electron energy of $1,4 \mathrm{MeV}$ and electron beam extraction into the air [33, 34]. The installation is expensive even though it has high capacity. Besides, upon evaporation in the atmosphere under normal pressure, formation of the large spherical and poorly agglomerated nanoparticles occurs. Those nanoparticles have a smaller density of various defects in contrast to the density of defects in the nanoparticles formed when produced in the vacuum.

Nevertheless, RTFM was observed in thin films of $\mathrm{ZnO}$ $C$ prepared by electron beam evaporation [35]. Data of the last researches of the $\mathrm{ZnO}-\mathrm{C}[35,36]$ system show that it is insufficiently studied and has large prospects. Thus, aside from the magnetism, the $\mathrm{ZnO}-\mathrm{C}$ system is quite promising because of its luminescent, optical properties [22, 37] and the increased photocatalytic activity $[38,39]$.

The purpose of this study was synthesis and research of structural properties of $\mathrm{ZnO}$ doped by carbon in small concentration by the method of target evaporation with the use of the pulsed electron beam in the vacuum and lowpressure gas [40].

\section{Experimental}

Nanopowders (NPs) of pure and carbon-doped $\mathrm{ZnO}$ were deposited on glass and titanic substrates on the nanobeam2 installation [40]. During the deposition, temperature of substrates was approximately at $373-473 \mathrm{~K}$. Residual air pressure in the vaporizing chamber did not exceed $4 \mathrm{~Pa}$. The distance between the target and the substrates was about $10-15 \mathrm{~cm}$. Mode of evaporation was as follows: an accelerating voltage: $40 \mathrm{kV}$, electron beam current: $0,4 \mathrm{~A}$, pulse length: $100 \mu$ s, pulse repetition rate: $100 \mathrm{~Hz}$, beam scanning on target: 2,5 $\mathrm{sm}^{2}$, and time of evaporation: 40-50 min.

Targets were prepared by mechanical stirring in a porcelain mortar of $\mathrm{ZnO}$ micron powders of pure for analysis (GOST 10262-73) with the specific surface area $S_{\text {ssa }}=2,7 \mathrm{~m}^{2}$ and spectral pure graphite (99.999). Concentration of added carbon was amounted to 0.1 and $0.5 \%$ wt. Mass of the targets with the diameter of $40 \mathrm{~mm}$ and height of $15-20 \mathrm{~mm}$ amounted to about 60-70 g.

All the NPs were deposited at room temperature and subsequently annealed at $773 \mathrm{~K}$ in air for $1 \mathrm{~h}$. The following diagnostics of nanopowders were used in the experiments. The percentages of $\mathrm{Fe}\left(x_{\mathrm{Fe}}\right)$ impurities in the samples were checked by an ELAN 9000 Perkin Elmer SCIEX (inductively coupled plasma (ICP)). Method of atomic absorption spectrophotometry (AAS) on Perkin-Elmer spectrometer was used for determination of carbon concentration.

The crystal structures of the $\mathrm{ZnO}(\mathrm{ZnO}-\mathrm{Zn})$ and $\mathrm{Zn}_{1-x} \mathrm{C}_{x} \mathrm{O}$ NPs and bulk samples were characterized by Shimadzu X-ray diffractometer XRD-7000 with nickel-filtered $\mathrm{Cu} \mathrm{K} \alpha$ radiation $(\lambda=0.154 \mathrm{~nm})$ in a $2 \theta$ range $20^{\circ}-90^{\circ}$. SEM images, EDX analysis, and elemental mapping were measured by scanning electron microscopes LEO982 with Oxford X-Ray Detector and LYRA3 TESCAN. The surface morphologies and sizes of the sample $\mathrm{ZnO}(\mathrm{ZnO}-\mathrm{Zn})$ were observed by a JEOL (Japan) JEM 2100 Transmission Electron Microscope (TEM) using an accelerating voltage of $200 \mathrm{kV}$. TEM was performed after the particles sedimented on carbon-coated copper grids. Specific surface area $\left(S_{\text {ssa }}\right)$ of NPs was defined by the Brunauer-Emmett-Teller method on the Micromeritics TriStar 3000 installation. Fast Fourier transform (FFT) was performed on lattice images with ImageJ software to obtain diffraction patterns. The magnetic measurements were performed on Cryogenic CFS-9T-CVTI vibrating sample magnetometer (VSM).

\section{Results and Discussions}

According to X-ray diffraction (XRD) upon evaporation of targets from pure $\mathrm{ZnO}$, two-phase amorphous-nanocrystalline powders $\mathrm{ZnO}-\mathrm{Zn}$ with $S_{\text {ssa }}=36 \mathrm{~m}^{2} / \mathrm{g}$ and high content of metal nanoparticles of zinc ( $40 \mathrm{wt} . \%)$ were produced. Further on, $\mathrm{ZnO}-\mathrm{Zn}$ NPs were annealed in the alundum crucibles on air at the temperature of $773 \mathrm{~K}$ within 1 hour in the chamber electric furnace.

Doped ZnO-C NPs were produced by evaporation of carbon-doped targets achieved by multiphase $\mathrm{ZnO}-\mathrm{Zn}$ C NPs and were also annealed at the temperature of $773 \mathrm{~K}$ within 1 hour. Annealing of NP, previously collected from glass substrates, was performed in the alundum crucibles. $\mathrm{ZnO}-\mathrm{Zn}-\mathrm{C}$ NPs, deposited on titanic substrates, were annealed together with substrates.

Prior to that, $\mathrm{ZnO}-\mathrm{Zn}(\mathrm{ZnO}-\mathrm{Zn}-\mathrm{C}) \mathrm{NP}$ had black color. After annealing, powders gained white color with a weak shade of gray.

Choice of annealing temperature was justified by the fact that annealing at the temperature over $773 \mathrm{~K}$ is very critical for magnetism in the $\mathrm{ZnO}$-based systems [29].

Results of measurements of $S_{\text {ssa }}$ and element composition of powders are presented in Table 1. It is obvious that concentration of iron impurity in a high doped sample of $\mathrm{ZnO}-\mathrm{C}$ (sample number 4, Table 1) is rather low, below 100 ppm.

X-ray diffraction patterns of annealed NPs of pure and carbon-doped $\mathrm{ZnO}\left(x_{\mathrm{C}}=0 ; 0.24\right.$ and $\left.0.25 \mathrm{wt} \%\right)$ are shown in Figure 1.

All peaks on diffraction patterns correspond to hexagonal wurtzite structure of $\mathrm{ZnO}$ with the space group P63mc (Joint Committee on Powder Diffraction Standards (JCPDS) the card number 36-1451). Additional peaks from pure carbon or carbon-containing phases are absent on the diffraction patterns. 
TABLE 1: The specific surface area $\left(S_{\mathrm{ssa}}\right)$ and concentration of Fe $\left(x_{\mathrm{Fe}}\right)$ and carbon $\left(x_{\mathrm{C}}\right)$ annealed at $773 \mathrm{~K}$ NPs on the basis of pure and carbondoped $\mathrm{ZnO}$.

\begin{tabular}{|c|c|c|c|c|c|}
\hline Number $^{* * *}$ & Target composition & $S_{\text {ssa }}, \mathrm{m}^{2} / \mathrm{g}$ & $x_{\mathrm{Fe}}, \mathrm{wt} \%,(\mathrm{ICP})$ & $x_{\mathrm{C}}, \mathrm{wt} \%(\mathrm{AAS})$ & $x_{\mathrm{C}}, \mathrm{wt} \%\left(\mathrm{EDX}^{* *}\right)$ \\
\hline 0 & $\mathrm{ZnO}_{\text {(pure for analysis) }}$ & 2.27 & - & - & - \\
\hline 1 & $\mathrm{ZnO}_{\text {vacuum }}$ & 7.39 & - & 0.22 & 2.30 \\
\hline $2^{*}$ & $\mathrm{ZnO}_{\text {air }}$ & - & - & 0.57 & - \\
\hline 3 & $\mathrm{ZnO}-0.1 \mathrm{wt} \% \mathrm{C}$ & 11.16 & - & 0.24 & 2.10 \\
\hline 4 & $\mathrm{ZnO}-0.5 \mathrm{wt} \% \mathrm{C}$ & 5.82 & $<0.01$ & 0.25 & 2.42 \\
\hline
\end{tabular}

${ }^{*}$ The sample number 2 is produced by evaporation of the target from $\mathrm{ZnO}$ with the air pressure of $20 \mathrm{~Pa}$.

** Average concentration of $x_{\mathrm{C}}$ from three sites of each sample is given.

*** Further, this numbering of NPs samples is used.

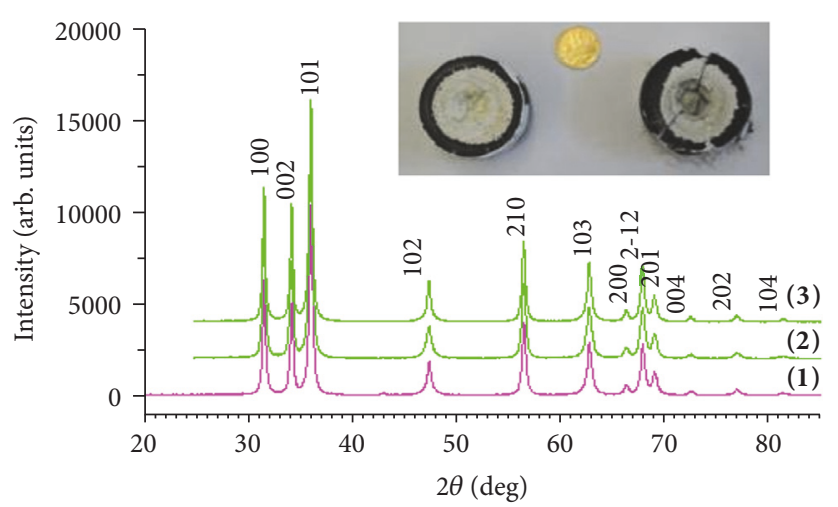

FIGURE 1: X-ray diffraction pattern of undoped (1) and carbon-doped ZnO: (2) $0.24 \% \mathrm{wt}$, (3) $0.25 \mathrm{wt} \%$, nanopowders annealed at $773 \mathrm{~K}$. On an insert, a photo of targets craters of samples number 3 and number 4 from Table 1; it is visible that color of the crater surface with high concentration of carbon is darker.

Relative comparison of ratios of the integral intensities I002/I100, I002/I101 of three main XRD peaks (100), (002) and (101) (Table 2) show that the sample of C-doped ZnO No. 3 had the smallest peak intensity (002).

At the beginning, relative peak intensity (002) decreases upon doping with carbon concentration growth $\left(x_{\mathrm{C}}\right)$. Further on, the relative intensity of the peak 002 increases again.

Crystal size was estimated using the Scherrer formula [41]. Results of the calculation presented in Table 2. It proves that carbon doping of pure $\mathrm{ZnO}$ stimulates primary growth of NPles along the direction $\langle 0001\rangle$ in coatings from ZnO NPles formed upon NPles deposition on the cold glass substrates; that is, nanocrystals growth in coatings occurs similar to crystals growth in thin films, with growth anisotropy in the direction of the $c$-axis in wurtzite $\mathrm{ZnO}$.

Relative growth of the peak 002 is indicative of the strengthening of crystals growth upon annealing in the direction of the axis $\langle 0001\rangle$ with carbon concentration increase. It is obvious from the Table 2 that the average size of crystallites in sample number $4(50 \mathrm{~nm})$ is significantly higher than in the slightly doped sample number $3(33 \mathrm{~nm})$. The ionic radius of $\mathrm{C}^{4-}(0.260 \mathrm{~nm})$ is much larger than that of $\mathrm{O}^{2-}(0.140 \mathrm{~nm})$ [14]; the substitution of $\mathrm{O}$ by $\mathrm{C}$ will expand the lattice. The expansion of the $\mathrm{ZnO}$ lattice might also originate from $\mathrm{C}$ atoms located at interstitial sites or from defects induced by pulsed electron beam evaporation.

Crystalline size was estimated using the Scherrer formula [41]. Results of the calculation presented in Table 2.
We will note that parameters of hexagonal lattice and their relation to $c / a$ for NPs of pure and doped $\mathrm{ZnO}$ (Table 2) considerably prevail over similar parameters of the microcrystalline standard. The slight variation of $a$ and $c$ may be due to partial substitution of lattice oxygen by carbon as well as the presence of interstitial carbon atoms in the $\mathrm{ZnO}$ lattice.

Determination of carbon concentration in the $\mathrm{ZnO}-\mathrm{C}$ system is not a trivial task. Carbon, stable at the room temperature, upon ambient temperature increase above $673 \mathrm{~K}$, begins to interact actively with residual oxygen atoms with carbon dioxide formation, which creates problems upon concentration assessment in the carbon-doped nanostructures [42]. Carbon concentration in NP samples was determined by the methods of atomic absorption spectrophotometry (AAS) and the energy dispersive X-ray (EDX). We will note that carbon concentration in $\mathrm{ZnO}-\mathrm{C}$ NP determined by the atomic absorption spectrophotometry methods (AAS) was slightly lower than in the targets $(0.24$ and $0.25 \mathrm{wt} . \%$ for targets $\mathrm{ZnO}-0.1 \mathrm{wt} \%$ and $\mathrm{ZnO}-0.5 \mathrm{wt} \% \mathrm{C}$, resp (Table 1)). On the contrary, $\mathrm{C}$ concentration in the samples determined by the EDX method was 10 times higher than the concentration estimates by the AAS method.

The following unwanted factors could also affect the observed mismatch in the concentration of carbon defined by the AAS and EDX methods: not enough fine vacuum in the scanning electron microscope (the microscope LEO982 had very old vacuum system) or hit of oil vapors into the 
TABLE 2: Parameters of crystal lattices $(a, c)$, the sizes of grains $(D)$, and the ratio of integrated intensity of the main diffraction peaks $(100)$, (002), and (101) in wurtzite lattices of NPs pure and carbon-doped $\mathrm{ZnO}$ after annealing.

\begin{tabular}{lcccccccccc}
\hline Number & Sample & $a, \AA$ & $c, \AA$ & $c / a$ & $D, \AA$ & ${ }^{*} I_{100}$ & ${ }^{*} I_{002}$ & ${ }^{*} I_{101}$ & $\left(I_{002} / I_{100}\right) * 100$ & $\left(I_{002} / I_{101}\right) * 100$ \\
\hline 1 & ZnOvacuum & $3.2529(7)$ & $5.2114(13)$ & 1.60207 & $400 \pm 30$ & $1902 \pm 15$ & $1488 \pm 14$ & $3656 \pm 16$ & 78 & 40 \\
3 & ZnO + C 0.1\% & $3.2531(6)$ & $5.2140(15)$ & 1.60277 & $330 \pm 30$ & $2300 \pm 20$ & $1730 \pm 20$ & $4410 \pm 30$ & 75 & 39 \\
4 & ZnO + C 0.5\% & $3.2529(6)$ & $5.2137(17)$ & 1.60278 & $500 \pm 30$ & $2038 \pm 18$ & $1673 \pm 17$ & $3853 \pm 18$ & 82 & 43 \\
Et $^{* *}$ & PDF 36-1451 & 3.249 & 5.206 & 1.60233 & - & 57 & 44 & 100 & 77 & 44 \\
\hline
\end{tabular}

* Integrated intensity is specified.

** Etalon.

researched samples in the course of their synthesis in installation NANOBIM-2, where oil-diffusion pumps for pumping of the evaporation camera are used. Similar divergence of carbon concentration in targets and C-doped $\mathrm{ZnO}$ thin films prepared by electron beam evaporation ("the nominally 1 at. $\%$ $\mathrm{C}$ sample was found to contain $0.25 \% \mathrm{C}$ while the nominally $3 \%$ sample contained $1.9 \%$ carbon") was observed in the process [35].

It is known [42] that determination of carbon concentration by AAS method is more preferable in comparison with the EDX method; therefore, further on we used the values of $\mathrm{C}$ concentration in the samples received by this method.

Evaporation in vacuum by means of the pulsed electron beam $[43,44]$ usually leads to high-temperature decomposition of $\mathrm{ZnO}$ with formation of a significant amount till 30-40 wt\% [45-47] of metal NPles of Zn, less than $5 \mathrm{~nm}$ in size (Figures 2(a) and 2(b)).

At the same time, oxide NPles in two-phase $\mathrm{ZnO}-\mathrm{Zn} \mathrm{NP}$ have a bit larger size, up to $15 \mathrm{~nm}$, than the restored metal NPles of $\mathrm{Zn}$. In fact, bimodal distribution of metal and oxide NPles by size is observed.

Quasi-spherical crystalline metal-oxide NPles of ZnO$\mathrm{Zn}$, in their turn, form agglomerates of NPles upon their receipt which is well visible on HRTEM picture (Figure 2(b)).

Figure 2(b) shows the interlayer spacing is about $0.285 \mathrm{~nm}$ which corresponds to the interlayer distance of the (100) crystal plane of wurtzite $\mathrm{ZnO}$.

We will note that the existence of the amorphous phase in $\mathrm{ZnO}-\mathrm{Zn}$ NPs was formed during NPles hardening upon their deposition on a cold substrate (usual windowpane glass). Figure 2(d) shows the fast FFT to amorphous region unannealed sample $\mathrm{ZnO}-\mathrm{Zn}$. Insets of Figure 2(c) are the corresponding FFT images from crystalline region.

Typical spherical core-shell $\mathrm{ZnO}-\mathrm{Zn}$ nanoparticle is shown in Figure 2(e). Thickness of the shell can reach nanometer units (3-5 nm) and both unevenly and not completely cover the crystal core.

SEM image of $\mathrm{ZnO}-\mathrm{Zn}$ NP previously deposited on titanic foil in vacuum and then annealed in air at the temperature of $500^{\circ} \mathrm{C}$ within 1 hour is presented in Figure 2(f). It is interesting that the agglomerated quasi-spherical NPles of $\mathrm{ZnO}-\mathrm{Zn}$ (Figures 2(a) and 2(b)), after annealing in air at $773 \mathrm{~K}$, were transformed into relatively poorly agglomerated quasi-spherical NPles (Figure 2) with sizes close to each other.

In the SEM image (Figure 2(f)) shown agglomerates consist of the spherical, almost monodisperse, NPles created after annealing. The size of the annealed spherical $\mathrm{ZnO}$
NPles does not exceed $50 \mathrm{~nm}$ which is consistent with the dependence of $\mathrm{ZnO}$ NPles size change during annealing on air as described in the study [48].

At the same time, average size of NPles in Figure 2(f) is consistent with the average size of grains determined by XRD analysis (Table 1 , sample number $1(40 \pm 3 \mathrm{~nm})$ ).

It can be considered as determined that in the result of $\mathrm{NP} \mathrm{ZnO}-\mathrm{Zn}$ annealing at $773 \mathrm{~K}$ the initial quasi-spherical metal-oxide NPles with bimodal distribution by the size were transformed to quasi-spherical NPles of ZnO less than $50 \mathrm{~nm}$ in size. Such transformation of the NPles formed during annealing indicates the strong recrystallization growth of metal particles of $\mathrm{Zn}$ after their oxidation, in the result of which sizes of the initial and newly formed NPles of $\mathrm{ZnO}$ align among each other.

It should be noted that, according to TG-DSC analysis, in the process of $\mathrm{ZnO}-\mathrm{Zn} \mathrm{NP}$ heating, oxidation of $\mathrm{Zn}$ metal particles in two-phase mixture begins at a very low temperature, about $430 \mathrm{~K}$ [49]. Moreover, in small concentrations (0.24 wt.\%) carbon-doped $\mathrm{ZnO}$ initially caused the size of grains to decrease from 40 to $30 \mathrm{~nm}$, which is confirmed by the high $S_{\text {ssa }}$ of the $\mathrm{ZnO}$-C sample $\left(S_{\text {ssa }}=11.16 \mathrm{~m}^{2} / \mathrm{g}\right.$, sample number 3, Table 1). Reduction of the grain size is possibly related to the replacement of oxygen atoms in $\mathrm{ZnO}$ lattice sites with small atoms of carbon.

According to XRD analysis, with the further growth of carbon concentration, the grain size increased up to $50 \mathrm{~nm}$ again. Growth of grain can be explained by simultaneous coexistence of two solution types in the lattice of $\mathrm{ZnO}$ substitutional solid solution and interstitial solid solution and also by the emergence of some quantity of free carbon which did not enter the $\mathrm{ZnO}$ lattice. The replacement of $\mathrm{Zn}$ ions with carbon ions $\left(\mathrm{C}_{\mathrm{Zn}}\right)$ and introduction of carbon in interstitials was observed in the study $[12,50]$.

Figure 3 shows the morphology of coatings from the NPles of pure and $\mathrm{C}$-doped $\mathrm{ZnO}$ deposited on a titanic foil and then annealed together with the foil on air at the temperature of $773 \mathrm{~K}$ within 1 hour. All coatings generally consist of NPles and spherical globules (droplets) of the micron size formed by these NPles. Bimodal distribution of particles by the size, typical for electron beam evaporation, is well visible $[45,51,52]$. We will also note the existence of an insignificant number of nanorods pointed at by the arrows in Figure 3(b). The biggest globules in the coating from pure $\mathrm{ZnO}$ have the size less than $1 \mu \mathrm{m}$; the size of the majority of globules does not exceed $0.5 \mu \mathrm{m}$. 


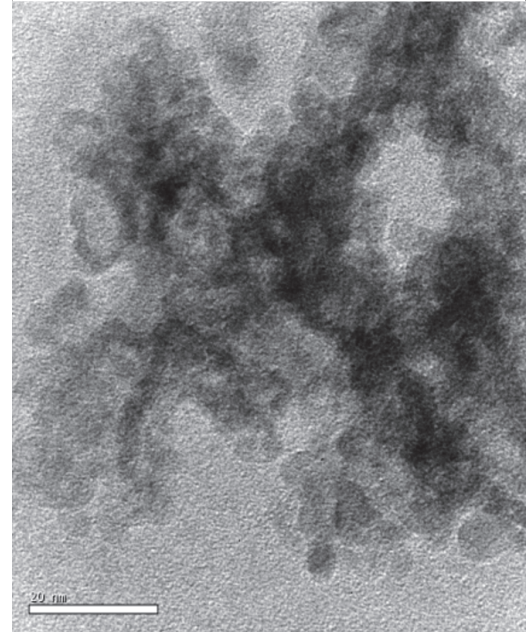

(a)

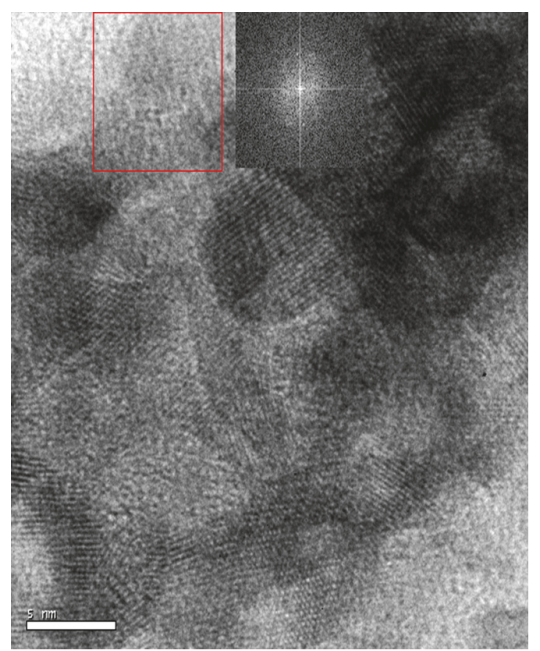

(d)

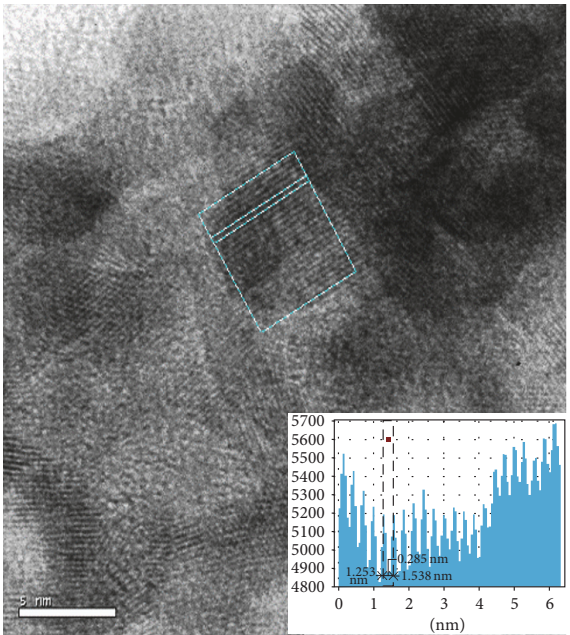

(b)

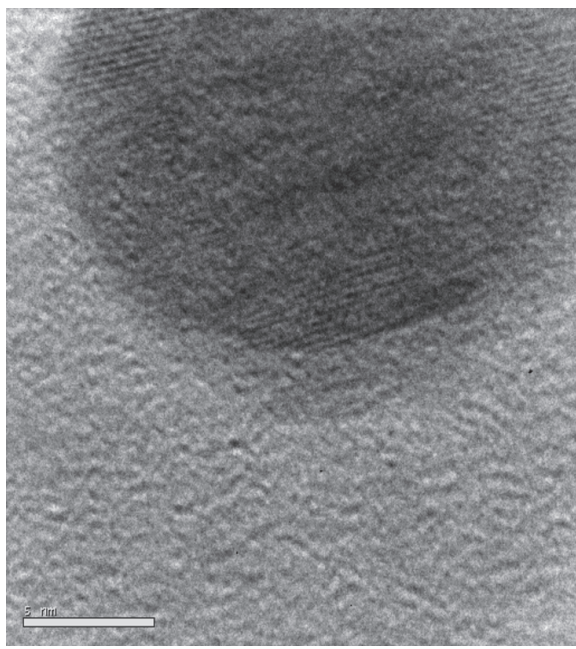

(e)

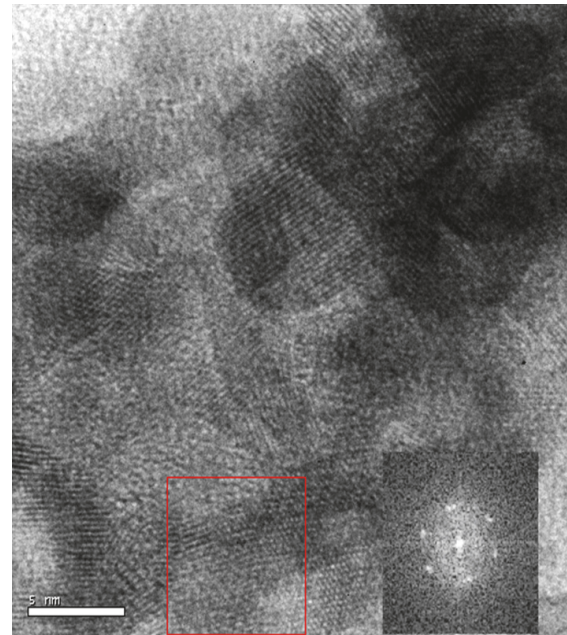

(c)

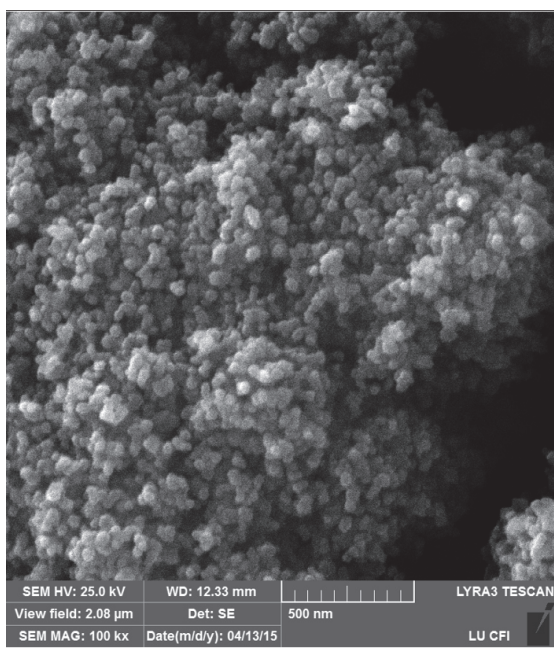

(f)

FIGURE 2: (a) TEM and (b, c, d, e) HRTEM images of amorphous-nanocrystalline NPles ZnO-Zn before annealing. Inset of (b) corresponds to the interlayer spacing which is about $0.285 \mathrm{~nm}$, which corresponds to the interlayer distance of the (100) crystal plane of wurtzite ZnO. Inset of (c) is the corresponding FFT image from crystalline region. Inset of (d) is the corresponding FFT image from amorphous region. (e) A core-shall $\mathrm{ZnO}$ NPle with coating thickness of $2.5 \mathrm{~nm}$; (f) SEM image of NPles ZnO-Zn annealed at $773 \mathrm{~K}$ in air for $1 \mathrm{~h}$. (SEM image in Figure 2(f) is executed by the employee of the Latvian State University (Latvia, Riga), A. Zolotarjovs.)

Upon carbon addition, the quantity of globules increases. The maximum size of globules reaches $3 \mu \mathrm{m}$ (Figure 3(c)); however, the structure of the coating will change significantly. Break down of globules of the average size $(0.5 \mu \mathrm{m})$ to the size less than $0.1 \mu \mathrm{m}$ occurs (Figure $3(\mathrm{~d})$ ). The surface of a globule resembles the form of a "sea hedgehog" (Figure $3(\mathrm{~g}))$. Judging by the numerous prints of the round and oval shape on a coating surface (shown by arrows in Figure 3(c)) remaining from the globules that have fallen off the coating, globules adhesion force with the surface is insignificant.

With the further increase of carbon concentration in a coating, noticeable growth of a number of large globules up to $3 \mu \mathrm{m}$ in size occurs. In Figure 3(e), the tendency towards size increase, surface smoothing (Figure $3(\mathrm{f})$ ), formation of globules of perfect spherical shape (Figure 3(h)), and, respectively, reduction of globules of the average size is well observed.

The change of coatings morphology on the basis of $\mathrm{ZnO}$ during doping as a result of the size change of the averagesized globules correlates well with the parameters of their $S_{\text {ssa }}$ (Table 2) and change of grain size from XRD data.

It should be pointed out that the spherical shape of globules, perfect, close to ideal, in sample number 4 (Figures $3(\mathrm{e}), 3(\mathrm{f})$, and $3(\mathrm{~h})$ ) indicates strong agglomeration of grains between each other which contributes to FM strengthening of $\mathrm{ZnO}$ particles, in accordance with the study conclusions $[53,54]$.

Upon doping, it is very important to receive homogeneous distribution of the dopant by volume or surface of the sample. For the research of uniformity of carbon distribution in the $\mathrm{ZnO}$ lattice, element mapping of samples 


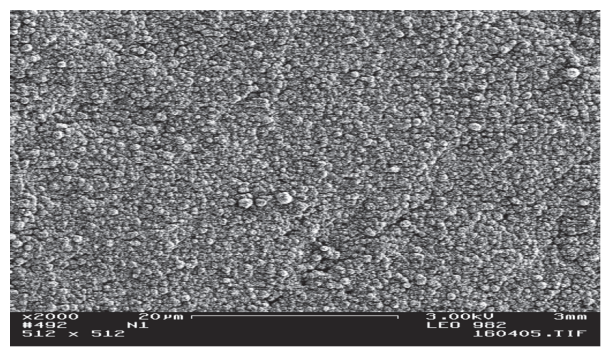

(a) Number 1

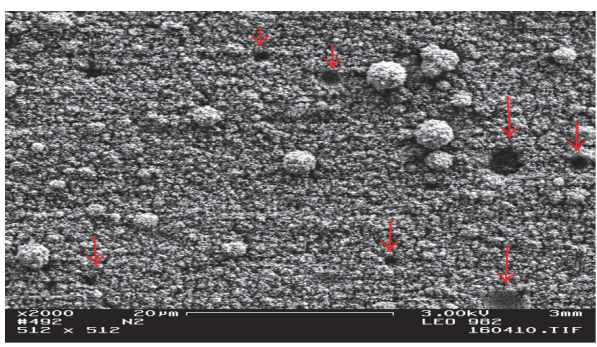

(c) Number 3

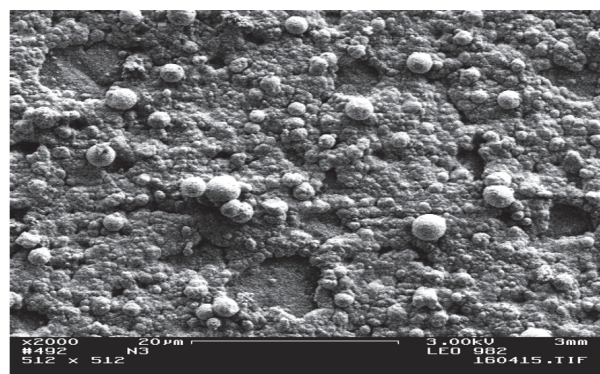

(e) Number 4

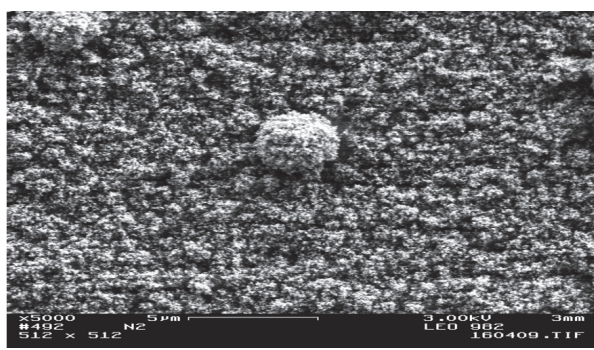

(g) Number 3

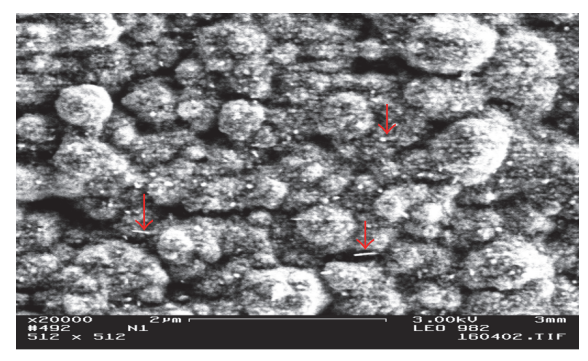

(b) Number 1

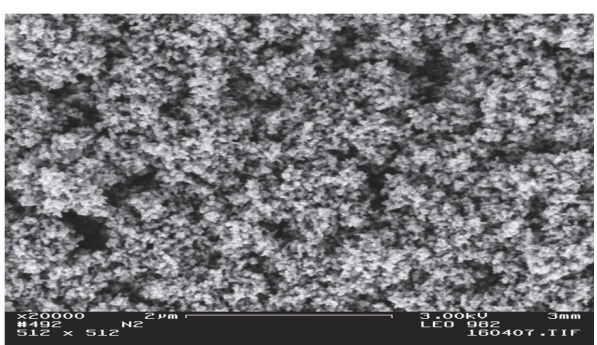

(d) Number 3

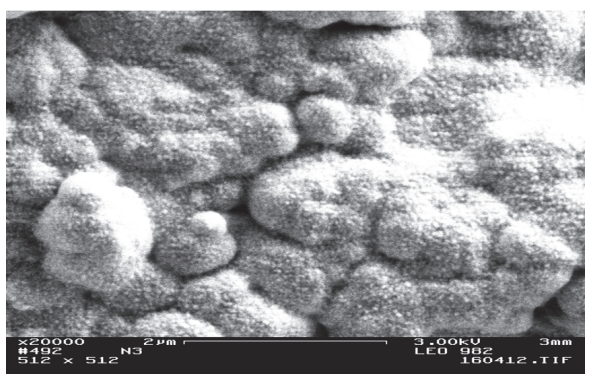

(f) Number 4

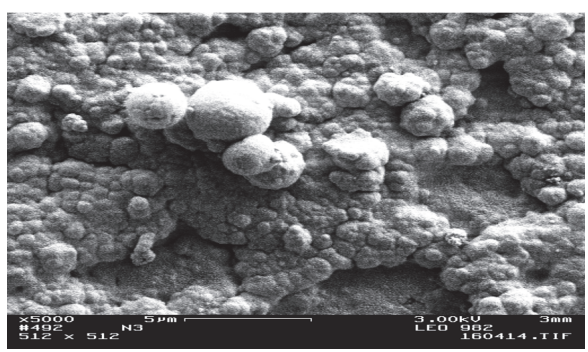

(h) Number 4

FIGURE 3: SEM images with various increases showing evolution of the forms annealed on a titanic foil at $773 \mathrm{~K}$ coatings from NPles: (a, b) pure $\mathrm{ZnO}$ (sample number 1) and carbon-doped samples: (c, d) sample number $3(2.4 \% \mathrm{C})$ and (e, f) sample number 4 (2.5\% C).

was implemented. Data of samples mapping with different concentrations of carbon are presented in Table 3.

Lack of clusters and homogeneous distribution of carbon in the samples is well visible. Comparison of color saturation on Table 3(e and $\mathrm{k}$ ) directly points to a big concentration of carbon in sample number 4 in contrast to sample number 3.

RTFM was found in all samples of pure and carbondoped $\mathrm{ZnO}$ produced with the use of pulsed electron beam evaporation.

S-shaped hysteresis loops Figure 4(a) were found in NPs samples of nondoped $\mathrm{ZnO}$ at the room temperature.
It is visible from Figure 4(a) that magnetization of the sample produced in vacuum exceeds magnetization of the sample evaporated in the air even after annealing almost twice. The identical form and symbate behavior of hysteresis loops of both samples indirectly prove that ferromagnetism (FM) of the samples is caused by the same type of defects.

Higher magnetization value of the sample evaporated in vacuum denotes higher concentration of structural vacancies $\left(V_{\mathrm{Zn}}\right.$ and/or $\left.V_{\mathrm{O}}\right)$ in sample number 1 as compared with sample number 2 (Table 1), which is natural, since nanoparticles formation took place upon oxygen deficiency. The S-shaped 
TABLE 3: Element mapping of samples number $1(\mathrm{a}-\mathrm{d}), 3(\mathrm{e}-\mathrm{h})$ and number $4(\mathrm{i}-\mathrm{l})$.

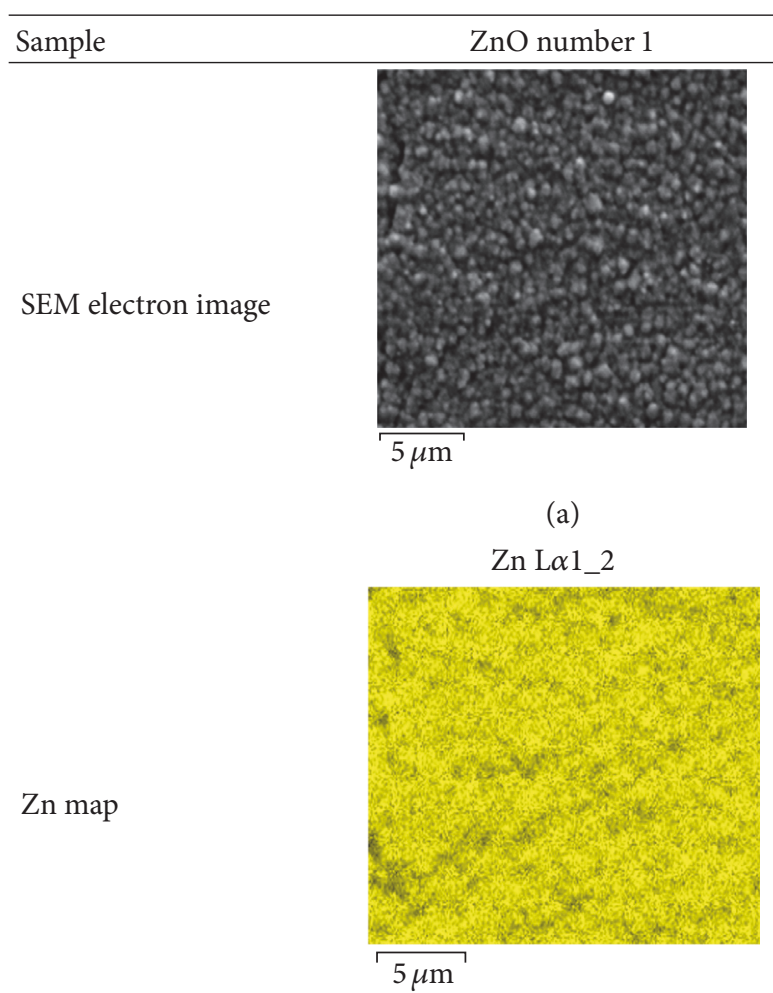

(b)

$\mathrm{O} \mathrm{K} \alpha 1$

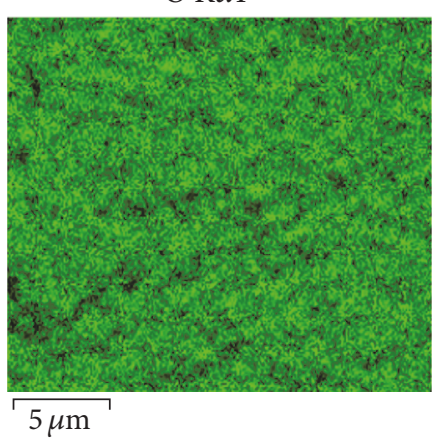

(c)

C K $\alpha 1 \_2$

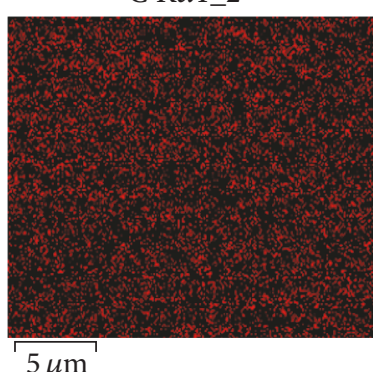

(d)

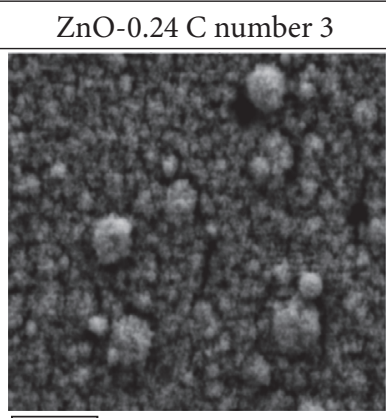

$5 \mu \mathrm{m}$

(e)

$\mathrm{Zn} \mathrm{L} \alpha 1 \_2$

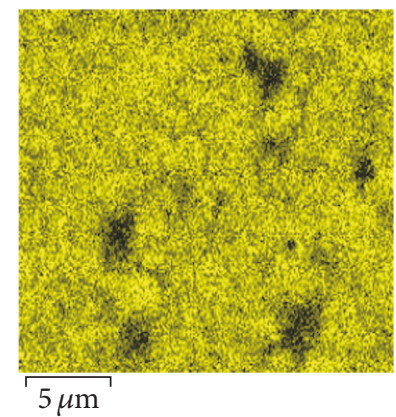

(f)

$\mathrm{O} \mathrm{K} \alpha 1$

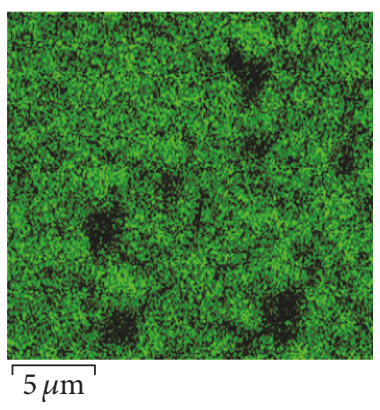

(g)

C K $\alpha 1 \_2$

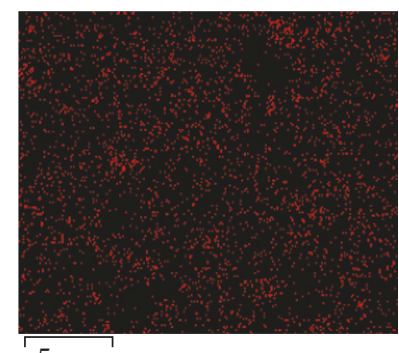

$5 \mu \mathrm{m}$
ZnO-0.25 C number 4

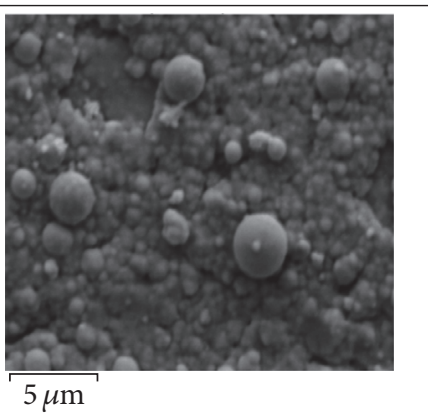

(i)

Zn L $\alpha 1 \_2$

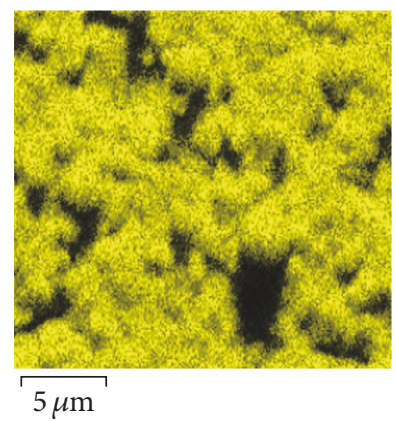

(j)

$\mathrm{O} \mathrm{K} \alpha 1$

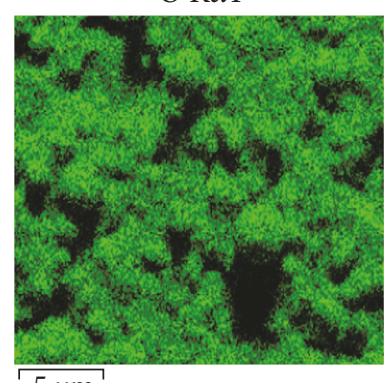

(k)

C K $\alpha 1 \_2$

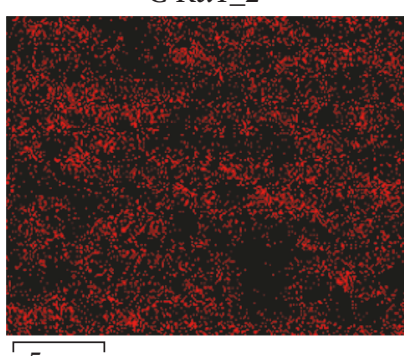

$\longdiv { 5 \mu \mathrm { m } }$

(h) 


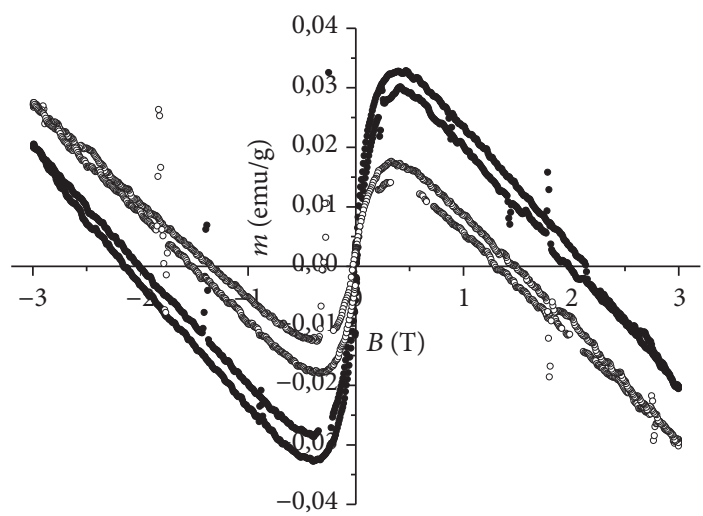

- Vacuum

- Air

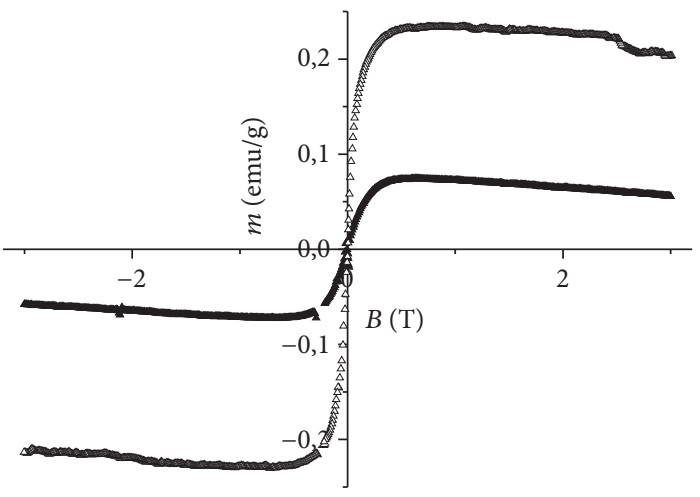

- $0,1 \% \mathrm{C}$

๑ $0,5 \% \mathrm{C}$

(a)

(b)

FIGURE 4: Dependence of specific magnetization on induction of a magnetic field, (a) the nondoped NP ZnO, produced in different conditions (in vacuum (number 1) and in the air atmosphere (number 2)) and then annealed in air at $773 \mathrm{~K}$, and (b) the carbon-doped NP ZnO with various concentrations of carbon: sample number $3,0.1 \mathrm{wt} \% \mathrm{C}$, and sample number $4,0.5 \mathrm{wt} \% \mathrm{C}$.

form of the hysteresis loop indicates superposition of ferroand diamagnetic responses in the samples.

Considering a significant error of magnetization measurement used in VSM magnetometer operation $(\Delta=$ $\pm 0.001 \mathrm{emu}$ ), comparison of absolute values of indicators of specific magnetization (emu/g), which are often comparable with the measuring background in terms of size, seems to be not quite correct. However, a qualitative assessment of the behavior of the magnetic moment is entirely permissible.

In the $\mathrm{ZnO}-\mathrm{C}$ system, suppression of diamagnetic components is expressed stronger than in $\mathrm{ZnO}$ samples No. 1 and 2. Nevertheless, S-shaped form of magnetization curves indicates superposition of two deposits, ferro- and diamagnetic, which indicates significant influence of $\mathrm{ZnO}$ lattice.

The anhysteretic form of magnetization curves of both samples (No. 3 and 4) indicates samples pursuance of superparamagnetism. Previously, superparamagnetism was observed in nondoped $\mathrm{ZnO}$ [55] as well, and it was explained by the cooperative streamlining of the superparamagnetic nanograins forming a cluster. Superparamagnetism was also found in the nondoped $\mathrm{ZnO}$ nanorods [56]. The anhysteretic magnetization curves of $\mathrm{C}$-doped $\mathrm{ZnO}$ thin films were obtained in the study [57].

Chemical analysis of sample number 4 with the maximum carbon concentration showed (Table 1) that content of Fe impurity does not exceed $0.01 \mathrm{wt} \%$ (100 ppm). Ferromagnetic response from such amount of iron impurity is considerably smaller than the observed magnetic response (Figure 4(b)); therefore, the impurity model of the magnetism is not applicable here.

Thus, in both doped $\mathrm{ZnO}-\mathrm{C}$ samples RTFM was clearly observed as a result of carbon inclusion into the $\mathrm{ZnO}$ matrix. The maximum magnetic moment is determined in the sample with the nominal content of of $2.4 \mathrm{wt} \% \mathrm{C}$. Earlier in $\mathrm{ZnO}-\mathrm{C}$ films, the maximum moment at $\mathrm{C}$ concentration of 1 at.\% $[14,35]$ and reduction of the magnetic moment at higher C concentrations 49 were observed. Such behavior was interpreted as a tendency of carbon atoms to be distributed nonuniformly at high concentrations.

In the research [58], the growth of magnetization with the increase of dopant concentration up to 2 at.\% was also observed. At $\mathrm{C}=2$ at.\%, the magnetization curve achieved saturation by the maximum of saturation of $M_{s}=1.1 \mathrm{emu} / \mathrm{g}$. Upon further carbon doping, only insignificant fluctuation of magnetization in films was detected.

Thus, the initial growth of magnetization of examined powders at small additives of carbon is quite consistent with the data of works $[13,58]$.

The RTFM mechanism in $\mathrm{ZnO}-\mathrm{C}$ has been earlier suggested by Pan et al. [13]. Strong interaction of s- and porbitals of carbon with s-orbital of zinc leads to splitting of $2 \mathrm{p}$ orbitals of carbon near the Fermi energy level, which provides primary contribution to the magnetic moment. Localized $2 p$ of the carbon spins are coupled with the holes in $\mathrm{O} 2 \mathrm{p}$ states generated in the result of oxygen replacement in sites with carbon. Such p-p interaction induces global ferromagnetism in the $\mathrm{ZnO}-\mathrm{C}$ system.

\section{Conclusion}

Pure and carbon-doped NPles of $\mathrm{ZnO}$ are synthesized by the method of the pulsed electron beam evaporation. The samples were annealed at the temperature of $773 \mathrm{~K}$. The XRD analysis confirmed the hexagonal wurtzite structure of the samples. With the growth of carbon concentration, the nonmonotonic change of lattice parameters and growth of crystal $\mathrm{ZnO}-\mathrm{C}$ grains were observed.

NPles sizes calculated according to the data of BET analysis are consistent with the NPles sizes received from $\mathrm{XRD}$ analysis.

It is found that $\mathrm{ZnO}$ doping by carbon stimulates the primary growth of NPles along the direction $\langle 0001\rangle$ in the coatings formed upon NPles deposition on the cold substrates; that is, nanocrystals growth in coatings occurs 
similar to crystals growth in thin films, with the growth anisotropy in the direction of the $c$-axis in wurtzite $\mathrm{ZnO}$. The SEM analysis has shown transformation of $\mathrm{ZnO}-\mathrm{Zn}$ NPles after annealing at the temperature of $773 \mathrm{~K}$ in monodispersed spherical $\mathrm{ZnO}$ NPles with an average size of about $50 \mathrm{~nm}$. With the growth of carbon concentration, the number of droplets on the surface of $\mathrm{ZnO}$ deposited on substrates increases.

The change of coatings morphology on the basis of $\mathrm{ZnO}$ during doping as a result of globules size change correlates well with the parameters of their $S_{\text {ssa }}$ and change of the grains size from XRD data. The element mapping confirmed homogeneous distribution of carbon in $\mathrm{ZnO}$ when using the method of pulsed electron evaporation of powders' mechanical mixtures. Magnetization of the annealed $\mathrm{ZnO}$ sample produced in vacuum is two times higher than magnetization of the annealed sample produced in the air atmosphere due to the higher density of oxygen vacancies in the sample formed in the oxygen deficiency. FM response of carbondoped samples was 5 times higher than the magnetic response of nondoped samples. With the growth of carbon concentration, magnetization of samples increased. Anhysteretic curves are indicative of $\mathrm{ZnO}-\mathrm{C}$ nanoparticles pursuance of superparamagnetism.

\section{Disclosure}

This manuscript has been presented as a poster in 13th International Conference Modification of Materials with Particle Beams and Plasma Flows.

\section{Conflicts of Interest}

The authors declare that they have no conflicts of interest.

\section{Acknowledgments}

The authors are grateful to the employee of IMET of the Ural Branch of the Russian Academy of Sciences (UB RAS), to Candidate of Chemical Sciences, S. V. Pryanichnikov, for the $\mathrm{X}$-ray phase analysis, to employees of IEP UB RAS: Junior Research Assistant, T. M. Demina, for measurement of a specific surface area and the DSC-TG-analysis, and to Candidate of Physical and Mathematical Sciences, A. M. Murzakaev, and Junior Research Assistant, O. R. Timoshenkova, for TEM and SEM shooting of samples. This study was done within the subject of the State Task no. 0389-2014-0005 and was partially supported by the Russian Foundation for Basic Research Project no. 15-08-01381.

\section{References}

[1] T. Dietl, "A ten-year perspective on dilute magnetic semiconductors and oxides," Nature Materials, vol. 9, no. 12, pp. 965-974, 2010.

[2] H. Ohno, "A window on the future of spintronics," Nature Materials, vol. 9, no. 12, pp. 952-954, 2010.
[3] J. M. D. Coey and S. A. Chambers, "Oxide dilute magnetic semiconductors-fact or fiction?" MRS Bulletin, vol. 33, no. 11, pp. 1053-1058, 2008.

[4] A. K. Das and A. Srinivasan, "Evidence of oxygen defect induced ferromagnetism in heat treated electrospun $\mathrm{ZnO}$ nanowires," Journal of Magnetism and Magnetic Materials, vol. 404, pp. 190-196, 2016.

[5] X. Hou, H. Liu, H. Sun, L. Liu, and X. Jia, "Significant roomtemperature ferromagnetism in porous $\mathrm{ZnO}$ films: the role of oxygen vacancies," Materials Science and Engineering B: SolidState Materials for Advanced Technology, vol. 200, pp. 22-27, 2015.

[6] T. L. Phan, Y. D. Zhang, D. S. Yang, N. X. Nghia, T. D. Thanh, and S. C. Yu, "Defect-induced ferromagnetism in $\mathrm{ZnO}$ nanoparticles prepared by mechanical milling," Applied Physics Letters, vol. 102, no. 7, Article ID 072408, 2016.

[7] R. N. Aljawf, F. Rahman, and S. Kumar, "Defects/vacancies engineering and ferromagnetic behavior in pure $\mathrm{ZnO}$ and $\mathrm{ZnO}$ doped with Co nanoparticles," Materials Research Bulletin, vol. 83, pp. 108-115, 2016.

[8] J. M. D. Coey, M. Venkatesan, and C. B. Fitzgerald, "Donor impurity band exchange in dilute ferromagnetic oxides," Nature Materials, vol. 4, no. 2, pp. 173-179, 2005.

[9] T. Dietl, "Dilute magnetic semiconductors: functional ferromagnets," Nature Materials, vol. 2, no. 10, pp. 646-648, 2003.

[10] S.-J. Sun, "Resonant valence bond states in zinc vacancies induce the ferromagnetism of $\mathrm{ZnO}$," Physics Letters A, vol. 380, no. 21, pp. 1872-1876, 2016.

[11] G. Xing, D. Wang, J. Yi et al., "Correlated d0 ferromagnetism and photoluminescence in undoped $\mathrm{ZnO}$ nanowires," Applied Physics Letters, vol. 96, no. 11, Article ID 112511, 2010.

[12] A. El Amiri, H. Lassri, E. K. Hlil, and M. Abid, "Explanation of ferromagnetism origin in $\mathrm{C}$-doped $\mathrm{ZnO}$ by first principle calculations," Journal of Magnetism and Magnetic Materials, vol. 374, pp. 338-341, 2015.

[13] H. Pan, J. B. Yi, L. Shen et al., "Room-temperature ferromagnetism in carbon-doped ZnO," Physical Review Letters, vol. 99, no. 12, Article ID 127201, 2007.

[14] S. Zhou, Q. Xu, K. Potzger et al., "Room temperature ferromagnetism in carbon-implanted ZnO," Applied Physics Letters, vol. 93, no. 23, Article ID 232507, 2008.

[15] T. S. Herng, S. P. Lau, L. Wang et al., "Magnetotransport properties of $\mathrm{p}$-type carbon-doped $\mathrm{ZnO}$ thin films," Applied Physics Letters, vol. 95, no. 1, Article ID 012505, 2009.

[16] J. W. Park, D. H. Kim, S.-H. Choi, M. Lee, and D. Lim, “The role of carbon doping in ZnO," Journal of the Korean Physical Society, vol. 57, no. 6, pp. 1482-1485, 2010.

[17] K. Tang, S. Gu, S. Zhu et al., "Carbon clusters in N-doped ZnO by metal-organic chemical vapor deposition," Applied Physics Letters, vol. 93, no. 13, Article ID 132107, 2008.

[18] X. Wang, X. Chen, R. Dong, Y. Huang, and W. Lu, "Ferromagnetism in carbon-doped $\mathrm{ZnO}$ films from first-principle study," Physics Letters A, vol. 373, no. 34, pp. 3091-3096, 2009.

[19] H. Lv, D. D. Sang, H. D. Li, X. B. Du, D. M. Li, and G. T. Zou, "Thermal evaporation synthesis and properties of $\mathrm{ZnO}$ nano/microstructures using carbon group elements as the reducing agents," Nanoscale Research Letters, vol. 5, no. 3, pp. 620-624, 2010

[20] N. D. Dung, C. T. Son, P. V. Loc et al., "Magnetic properties of sol-gel synthesized C-doped $\mathrm{ZnO}$ nanoparticles," Journal of Alloys and Compounds, vol. 668, pp. 87-90, 2016. 
[21] J. B. Yi, L. Shen, H. Pan et al., "Enhancement of room temperature ferromagnetism in C-doped $\mathrm{ZnO}$ films by nitrogen codoping," Journal of Applied Physics, vol. 105, no. 7, Article ID 07C513, 2009.

[22] N. Tu, K. T. Nguyen, D. Q. Trung, N. T. Tuan, V. N. Do, and P. T. Huy, "Effects of carbon on optical properties of $\mathrm{ZnO}$ powder," Journal of Luminescence, vol. 174, pp. 6-10, 2016.

[23] X.-L. Li, J.-F. Guo, Z.-Y. Quan, X.-H. Xu, and G. A. Gehring, "Defects inducing ferromagnetism in carbon-doped $\mathrm{ZnO}$ films," IEEE Transactions on Magnetics, vol. 46, no. 6, pp. 13821384, 2010.

[24] F. Pan, C. Song, X. J. Liu, Y. C. Yang, and F. Zeng, "Ferromagnetism and possible application in spintronics of transitionmetal-doped ZnO films," Materials Science and Engineering $R$ : Reports, vol. 62, no. 1, pp. 1-35, 2008.

[25] P. Zhan, W. Wang, C. Liu et al., "Oxygen vacancy-induced ferromagnetism in un-doped $\mathrm{ZnO}$ thin films," Journal of Applied Physics, vol. 111, no. 3, Article ID 033501, 2012.

[26] P. Mohanty, D. Kabiraj, R. K. Mandal, P. K. Kulriya, A. S. K. Sinha, and C. Rath, "Evidence of room temperature ferromagnetism in argon/oxygen annealed $\mathrm{TiO} 2$ thin films deposited by electron beam evaporation technique," Journal of Magnetism and Magnetic Materials, vol. 355, pp. 240-245, 2014.

[27] I. N. Reddy, V. R. Reddy, A. Dey et al., "Microstructural studies of e-beam evaporated alumina thin films," Surface Engineering, vol. 30, no. 8, pp. 594-599, 2014.

[28] I. Neelakanta Reddy, N. Sridhara, P. Bera, C. Anandan, A. Kumar Sharma, and A. Dey, "Nanostructured alumina films by E-beam evaporation," Ceramics International, vol. 41, no. 9, pp. 10537-10546, 2015.

[29] S. Ning, P. Zhan, W. Wang, Z. Li, and Z. Zhang, "Defect characterization and magnetic properties in un-doped $\mathrm{ZnO}$ thin film annealed in a strong magnetic field," Chinese Physics B, vol. 23, no. 12, Article ID 127503, 2014.

[30] A.-A. El Mel and C. Bittencourt, "In situ conversion of nanostructures from solid to hollow in transmission electron microscopes using electron beam," Nanoscale, vol. 8, no. 21, pp. 10876-10884, 2016.

[31] M. Nistor, N. B. Mandache, and J. Perrière, "Pulsed electron beam deposition of oxide thin films," Journal of Physics D: Applied Physics, vol. 41, no. 16, Article ID 165205, 2008.

[32] M. Nistor, A. Petitmangin, C. Hebert, and W. Seiler, "Nanocomposite oxide thin films grown by pulsed energy beam deposition," Applied Surface Science, vol. 257, no. 12, pp. 5337-5340, 2011.

[33] S. P. Bardakhanov, A. I. Korchagin, N. K. Kuksanov et al., "Nanopowder production based on technology of solid raw substances evaporation by electron beam accelerator," Materials Science and Engineering: B, vol. 132, no. 1-2, pp. 204-208, 2006.

[34] A. I. Korchagin, N. K. Kuksanov, A. V. Lavrukhin et al., "Production of silver nano-powders by electron beam evaporation," Vacuum, vol. 77, no. 4, pp. 485-491, 2005.

[35] S. Akbar, S. K. Hasanain, M. Abbas, S. Ozcan, B. Ali, and S. I. Shah, "Defect induced ferromagnetism in carbon-doped $\mathrm{ZnO}$ thin films," Solid State Communications, vol. 151, no. 1, pp. 1720, 2011.

[36] N. Tu, N. Dung, N. Lan et al., "Enhanced ferromagnetism in graphite-like carbon layer-coated $\mathrm{ZnO}$ crystals," Journal of Alloys and Compounds, vol. 695, pp. 233-237, 2017.

[37] Y. H. Lu, Z. X. Hong, Y. P. Feng, and S. P. Russo, "Roles of carbon in light emission of ZnO," Applied Physics Letters, vol. 96, no. 9, Article ID 091914, 2010.
[38] W. Yu, J. Zhang, and T. Peng, "New insight into the enhanced photocatalytic activity of N-, C- and S-doped $\mathrm{ZnO}$ photocatalysts," Applied Catalysis B: Environmental, vol. 181, pp. 220-227, 2016.

[39] M. Samadi, M. Zirak, A. Naseri, E. Khorashadizade, and A. Z. Moshfegh, "Recent progress on doped $\mathrm{ZnO}$ nanostructures for visible-light photocatalysis," Thin Solid Films, pp. 2-19, 2016.

[40] S. Y. Sokovnin and V. G. Il'Ves, "Production of nanopowders using pulsed electron beam," Ferroelectrics, vol. 436, no. 1, pp. 101-107, 2012.

[41] H. P. Klug and L. E. Alexander, Eds., X-Ray Diffraction Procedures: For Polycrystal-Line and Amorphous Materials, John Wiley \& Sons, New York, NY, USA, 1962.

[42] C. S. Wei, Ferromagnetism in carbon-doped $\mathrm{ZnO}$ thin films and nanostructures [Doctor of Philosophy], The Hong Kong Polytechnic University, 2011.

[43] V. G. Il'ves and S. Y. Sokovnin, "Effect of iron doping on the structural and magnetic properties of $\mathrm{ZnO}$ nanoparticles prepared by pulsed electron beam evaporation," Physics of the Solid State, vol. 56, no. 11, pp. 2273-2285, 2014.

[44] S. Y. Sokovnin and V. G. Il'Ves, "Production of nanopowders using pulsed electron beam," Ferroelectrics, vol. 436, no. 1, pp. 101-107, 2012.

[45] V. G. Il'ves and S. Y. Sokovnin, "Production of $\mathrm{ZnO}$ and $\mathrm{Zn}-\mathrm{ZnO}$ nanopowders using evaporation by a pulsed electron beam in low-pressure gas," Nanotechnologies in Russia, vol. 6, no. 1-2, pp. 137-143, 2011.

[46] V. S. Burakov, N. V. Tarasenko, E. A. Nevar, and M. I. Nedel'ko, "Morphology and optical properties of zinc oxide nanostructures synthesized by the methods of thermal and discharge sputtering," Technical Physics, vol. 56, no. 2, pp. 245-253, 2011.

[47] D. Chhikara, M. Senthil Kumar, and K. M. K. Srivatsa, "On the synthesis of $\mathrm{Zn} / \mathrm{ZnO}$ core-shell solid microspheres on quartz substrate by thermal evaporation technique," Superlattices and Microstructures, vol. 82, pp. 368-377, 2015.

[48] D. Wang, Z. O. Chen, D. D. Wang et al., "Positron annihilation study of the interfacial defects in $\mathrm{ZnO}$ nanocrystals: correlation with ferromagnetism," Journal of Applied Physics, vol. 107, no. 2, Article ID 023524, 8 pages, 2010.

[49] S. Y. Sokovnin, V. G. Il'Ves, A. I. Medvedev, and A. M. Murzakaev, "Investigation of properties of $\mathrm{ZnO}-\mathrm{Zn}$-Cu nanopowders obtained by pulsed electron evaporation," Inorganic Materials: Applied Research, vol. 4, no. 5, pp. 410-419, 2013.

[50] S. K. Nayak, M. E. Gruner, S. Sakong et al., "Anisotropic ferromagnetism in carbon-doped zinc oxide from first-principles studies," Physical Review B-Condensed Matter and Materials Physics, vol. 86, no. 5, Article ID 054441, 2012.

[51] A. Y. Vovk, J.-Q. Wang, W. Zhou et al., "Room temperature tunneling magnetoresistance of electron beam deposited $\left(\mathrm{Co}_{50} \mathrm{Fe}_{50}\right)_{x}\left(\mathrm{Al}_{2} \mathrm{O}_{3}\right)_{1-x}$ cermet granular films," Journal of Applied Physics, vol. 91, no. 12, pp. 10017-10021, 2002.

[52] A. V. Samokhin, N. V. Alexeev, A. V. Vodopyanov, D. A. Mansfeld, and Y. V. Tsvetkov, "Metal oxide nanopowder production by evaporationcondensation using a focused microwave radiation at a frequency of $24 \mathrm{GHz}$," Journal of Nanotechnology in Engineering and Medicine, vol. 6, no. 1, Article ID 011008, 2016.

[53] B. B. Straumal, S. G. Protasova, A. A. Mazilkin et al., "Ferromagnetism of zinc oxide nanograined films," JETP Letters, vol. 97, no. 6, pp. 367-377, 2013. 
[54] S. Banerjee, M. Mandal, N. Gayathri, and M. Sardar, "Enhancement of ferromagnetism upon thermal annealing in pure $\mathrm{ZnO}$," Applied Physics Letters, vol. 91, no. 18, Article ID 182501, 2007.

[55] B. Ghosh, M. Sardar, and S. Banerjee, "Cooperative ordering of superparamagnetic $\mathrm{ZnO}$ nanograins," https://arxiv.org/abs/ 1010.2381.

[56] O. Koshy and M. A. Khadar, "Superparamagnetism in undoped ZnO nanorods," Applied Surface Science, vol. 346, pp. 528-533, 2015.

[57] H. S. Hsu, Y. Tung, Y. J. Chen, M. G. Chen, J. S. Lee, and S. J. Sun, "Defect engineering of room-temperature ferromagnetism of carbon-doped ZnO," Physica Status Solidi (RRL)-Rapid Research Letters, vol. 5, no. 12, pp. 447-449, 2011.

[58] Y. W. Ma, Room tepmeaterature ferromagnetism in $\mathrm{ZnO}$ based magnetic semiconductors and carbon related systems [doctor of philosophy], Department of Materials Science and Engineering, National University of Singapore, 2011, http://www.scholarbank .nus.edu.sg/bitstream/handle/10635/27898/MAYW.pdf?sequence $=1$. 

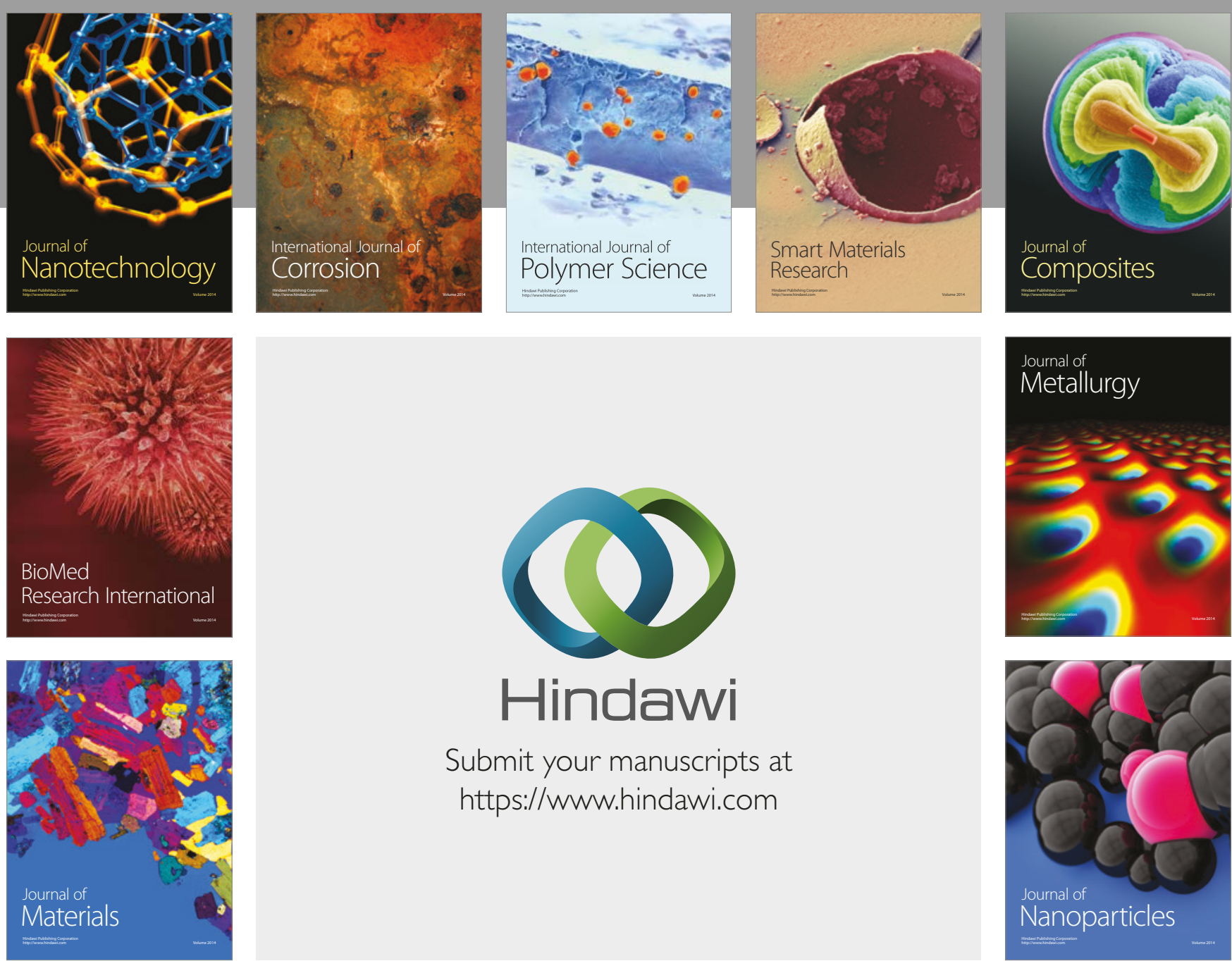

\section{Hindawi}

Submit your manuscripts at

https://www.hindawi.com
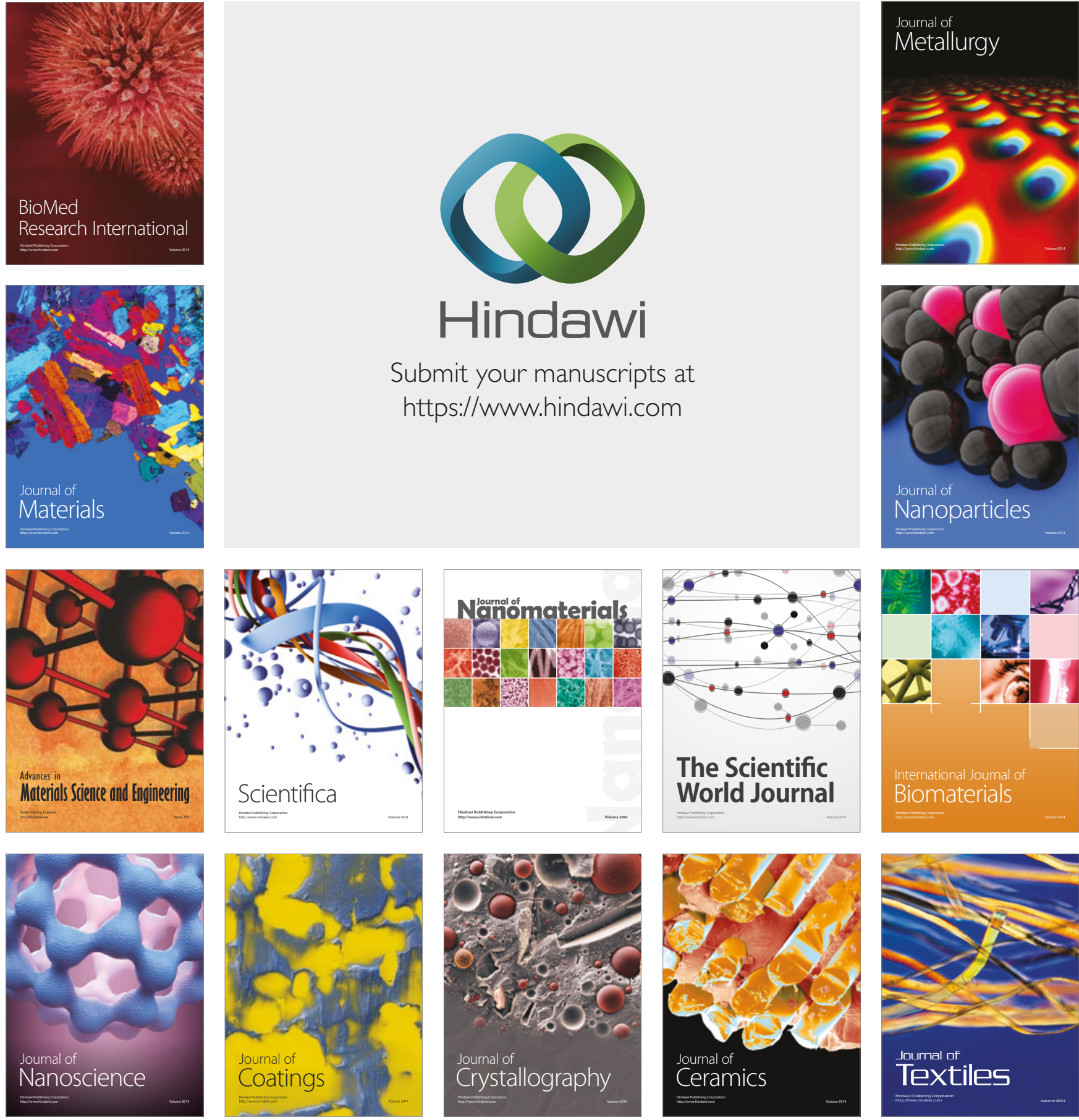

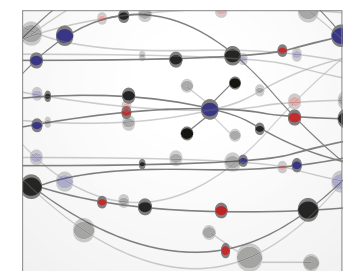

The Scientific World Journal
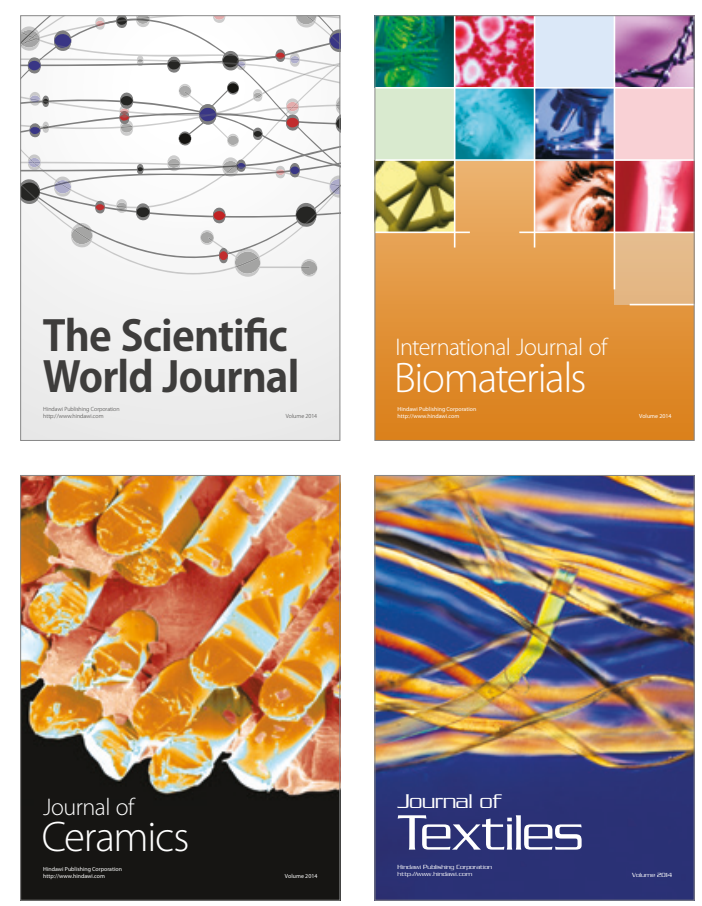